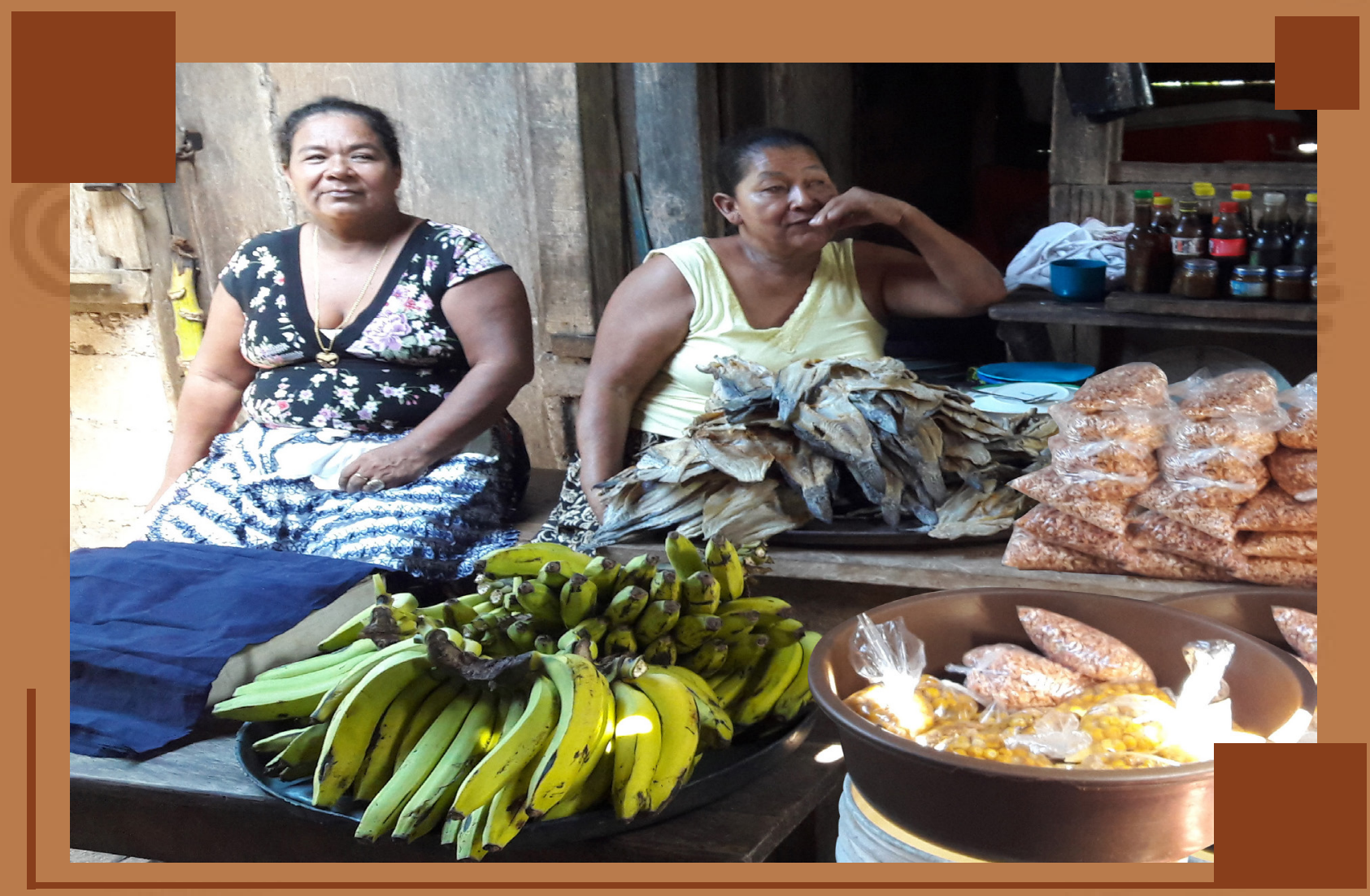

Realidades interculturales entre las mujeres miskitas, creole y mestizas en la ciudad de Bilwi, municipio Puerto Cabezas, RACCN

Pueblo, Cultura e Identidad 


\title{
Realidades interculturales entre las mujeres miskitas, creole y mes- tizas en la ciudad de Bilwi, municipio Puerto Cabezas, RACCN
}

\section{Intercultural realities among Miskito, Creole and mestizo women in the city of Bilwi, Puerto Ca- bezas municipality, RACCN}

Dayaisi Grissell López Ramírez

Recibido: 15-10-2019

Antropóloga, Investigador independiente

ID Orcid: https://orcid.org/0000-0003-4678-2207

dayaisilr@gmail.com

\section{Resumen}

El presente artículo sobre las realidades interculturales entre las mujeres de los grupos étnicos Miskito, Creole, y Mestizo en la ciudad de Bilwi, Municipio Puerto Cabeza, RACCN. La ciudad de Bilwi se caracteriza por ser multiétnica y plurilingüe, debido a la diversidad de etnias presentes en la población. Se observa y analiza su vida cotidiana y sus relaciones interculturales desde la cosmovisión de las mujeres costeñas, con el propósito de identificar como se construyen y entretejen. Lo que se logró identificar, es que los grupos étnicos figuran a la mujer dentro de sus prácticas culturales como indispensables, al igual que dentro de sus sistema de creencias y herencia cultural, la identidad de las mujeres en cuanto a sus orígenes étnicos está presente, el protagonismo de las mujeres está fuertemente ligados a los procesos de interculturalidad y la conformación de las familias inter-étnicas abren paso a las percepciones de las mujeres en cuanto al ser mujer costeña dentro de la Ciudad de Bilwi. Todo con el propósito de poder proyectar la importancia de las investigaciones que engloban el mejor entendimiento de las culturas, las poblaciones y la realidad social que se vive en la Región de la Costa Caribe Norte de Nicaragua, desde la cosmovisión, vivencias y experiencias de la misma población Costeña bajo la mira de las mujeres, pues son indispensables para el desarrollo integral de la Ciudad de Bilwi.

Palabras claves: Interculturalidad, Identidad, Mujer, Etnia, Cosmovisión.

\begin{abstract}
The present Research work is related to the intercultural realities among the women of the Miskito, Creole, and Mestizo ethnic groups in the city of Bilwi, Puerto Cabeza Municipality, RACCN. The city of Bilwi is characterized by being multiethnic and multilingual. Due to the diversity of ethnicities present within the population, from the cosmovision of coastal women, their daily life and intercultural relations with The purpose of identifying how and why they occur, from the perspective of women. What it was possible to identify is that ethnic groups figure women within their cultural practices as indispensable, as well as within their belief and cultural heritage system, the identity of women in terms of their ethnic origins is present, The role of women is strongly linked to the processes of interculturality and the formation of inter-ethnic families open the way to women's perceptions of being a coastal woman within the City of Bilwi. All with the purpose of being able to project the importance of research that encompasses the best understanding of cultures, populations and the social reality that is lived in the Region of the North Caribbean Coast of Nicaragua, from the worldview, experiences and experiences of the The same population of Costa Rica under the eye of women, as they are indispensable for the integral development of the City of Bilwi.
\end{abstract}

Keywords: Interculturality, Identity, Woman, Ethnicity, Worldview. 
Las relaciones interculturales entre las mujeres costeñas, desde su propia cosmovisión, es el interés de este texto.

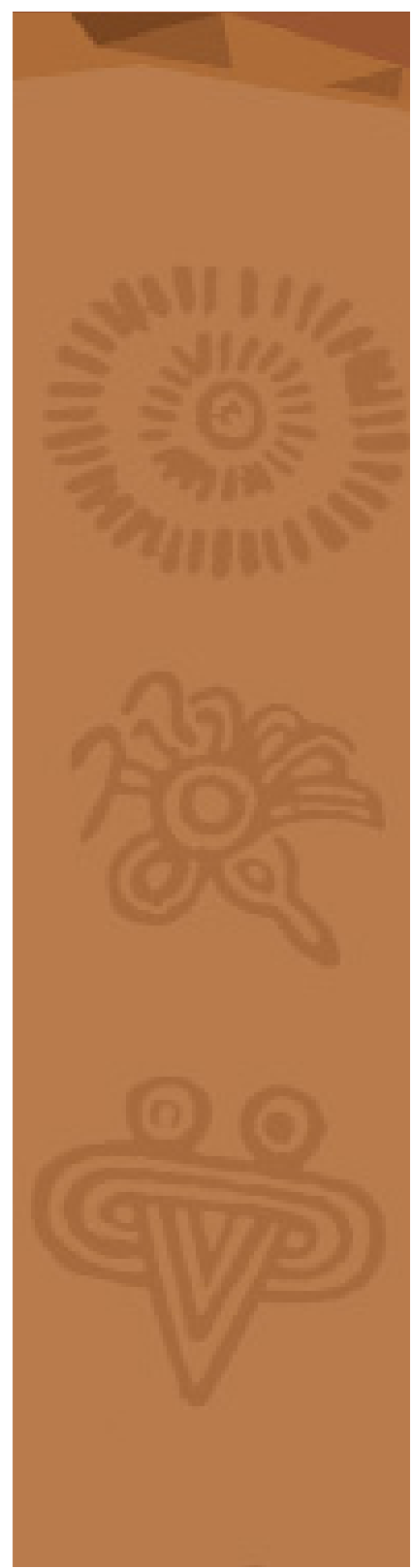

\section{Introducción}

La Región Autónoma de la Costa Caribe Norte se caracteriza por ser pluricultural y multilingüe, haciendo referencia a que ésta alberga una diversidad cultural debido a las etnias existentes dentro de la misma, muchas investigaciones se han realizado en relación a los grupos étnicos; sin embargo, ninguno que implique a las mujeres y su punto de vista ante la interculturalidad dentro del contexto urbano.

Las relaciones interculturales entre las mujeres costeñas, desde su propia cosmovisión, es el interés de este texto. Tomando en cuenta el rol que desempeñan las mujeres dentro de la sociedad, espacios laborales y el hogar expandimos el campo investigativo a lo cotidiano dentro del diario vivir de las mujeres costeñas.

Realizar investigaciones que aborden estos temas abona entender la realidad intercultural y el protagonismo de las mujeres dentro del contexto, entender la cultura, el multiculturalismo e interculturalidad de la mano del multilingüismo, desde la cosmovisión de las mujeres, nos dan una perspectiva diferente de lo que implica el género dentro de la Ciudad de Bilwi.

Desde la antropología de igual forma se realizan análisis de la realidad de la vida cotidiana de las mujeres y cómo sus prácticas se han venido modificado por la interacción social intercultural, bajo una investigación que se aleja del androcentrismo.

La revista WANI ha tratado diferentes temas culturales y sociales como, la interculturalidad en el discurso de los niños Miskitos en Corn Island. En ese artículo, se considera la interculturalidad como "un lema común en discursos educativos y públicos en la Costa Caribe de Nicaragua, y parece una manera lógica de conceptualizar las fluidas y múltiples formas de socialización del lenguaje que he descrito" (Minks, 2003).

También tenemos otro aporte sobre el tema de la interculturalidad, en relación a la cosmovisión Miskita de las comunidades, donde se explica "La cosmovisión es considerada como la forma de valorar la vida y sus orígenes, todo lo que nos rodea, así como la interrelación con la naturaleza"(Benk, Balderramos Rojas, \& Espinosa Blanco, 2016).

\section{Mujer, Género y cosmovisión: una triada intercultural}

Temas elementales como la cultura deben de ser definidos puesto que la cultura nos ayuda a comprender la cosmovisión de un grupo étnico con respecto a todo lo que le rodea, existen diversas teorías en relación al tema, en este caso particular el antropólogo Clifford Geertz en su libro: "La interpretación de las culturas" afirma que: 
La cultura denota un esquema históricamente trasmitido de significaciones representadas en símbolos, un sistema de concepciones heredadas y expresadas en formas simbólicas por medios con los cuales los hombres comunican, perpetuán y desarrollan conocimientos y sus actitudes frente a la vida. (Geertz, 1973, pág. 88)

La cultura nos ayuda a comprender mejor la cosmovisión de los grupos étnicos y en este caso particular el interés en conocer la percepción de la mujer dentro del mismo, temas como el género y lo que este representa serán abordados, La Socióloga Miriam E. de la Torre Vázquez aporta una propuesta teórica sobre el género al asegurar que:

El género determina culturalmente el ser y el hacer de manera profunda, como asumirá sus roles y estereotipos, y por supuesto también la manera en que vivirá su intimidad sexual. (Vázquez, 2017, pág. 94)

La relevancia del tema acerca del género representa un punto clave, dentro de este tema se abren debates en relación a lo que debe de representar el ser hombre o mujer por su género preestablecido ya sea por la sociedad o su grupo étnico. Es entonces cuando enfocamos la mirada en el "ser mujer" y lo que representa, para esto nos referimos a el planeamiento de Judith Butler que en su libro "El género en disputa, el feminismo y la subversión de la identidad", ofrece una interpretación por definición el término Mujer.

El termino $<<$ mujer $>>$ indica una identidad común. En lugar de un significante estable que reclama la aprobación de aquellas a quienes pretende describir y representar. (Butler, 1999, pág. 49)

Es decir, el concepto de "mujer" es visto como una identidad prescrita para identificar a un ser humano, pues no representa simbólicamente lo mismo para todas aquellas a quienes se le llama mujer. Desde el contexto se puede añadir la pertinencia de esta interpretación, pues como ya lo hemos mencionado cada grupo étnico tiene una percepción en cuanto a lo que representa el ser mujer y las mujeres en sí, sin importar que sea un común denominador para refiriese a ellas.

De este modo es indispensable abordar la cosmovisión, es aquí donde entendemos el porqué, cómo y cuándo las mujeres en este particular perciben su cultura. "La cosmovisión se puede describir como lentes, modelo o mapa desde el punto de vista del cual las personas perciben la realidad" (Sánchez, 2010, pág. 80).

Estos elementos son abordados, debido al protagonismo que tienen las mujeres como actoras activas de intercambios interculturales dentro de un contexto multiétnico. De este modo damos paso a los siguientes elementos teóricos en relación a las características del contexto de estudio, para fortalecer y dirigir las diferentes temáticas que son abordadas a lo largo del documento. 


\section{Identidades interculturales: Diálogo entre culturas}

Las identidades interculturales surgen durante la interacción social, el contacto con otros grupos étnicos y la creación de un sentido de pertenecía entre sí, esto sucede generalmente cuando existe una convivencia dentro de un mismo contexto, como en la ciudad de Bilwi, multiétnica y multilingüe.

Existe diferentes culturas ó grupos étnicos, pero ¿qué pasa cuando coexisten dentro de un mismo contexto?, esta es la situación que se presenta en la investigación, "Multiculturalismo suele entenderse como el reconocimiento de la coexistencia de grupos culturales diferentes dentro de un mismo estado nación" (Barabas, 2014, pág. 2). Del mismo modo surge la "Pluralidad de culturas que conviven de hecho en el seno de estados nacionales (pluralismo de hechos)” (Barabas, 2014, pág. 2).(ídem)

A raíz de esto podemos identificar lo siguiente; el conjunto de la existencia de los grupos étnicos, su coexistencia dentro de un mismo contexto, lo que conlleva a la interacción intercultural.

La interculturalidad se entiende como un proceso vigente y dinámico. El reto está en cómo construir un dialogo de saberes y de formas de ser diferentes en matrices culturales derivadas de mundos de vida distintos y, sobre todo, de construcciones dominantes/ dominadas a través de las cuales se construye la cotidianidad (Salinas \& Juárez Núñez, 2013, pág. 21).

El diálogo entre culturas hace referencia a un intercambio de conocimientos y saberes, aceptar y respetar al otro, inclusión cultural para lograr una relación social balanceada, el reto y realidad de contextos como la ciudad de Bilwi.

\section{Metodología}

Este artículo es el resultado de una tesis de investigación trabajado a lo largo de dos años y medio en la ciudad de Bilwi, Puerto Cabezas. El trabajo de campo fue realizado desde el primer semestre del año 2016 hasta el año 2019. Las estancias en el contexto han variado, puesto que en algunas ocasiones fueron tres meses y en otros momentos por una semana en tiempos festivos.

En el trabajo de campo se aplicó el método etnográfico, a través del cual se seleccionaron algunas festividades costeñas, por ser un espacio de relaciones interculturales. Por lo tanto, entre 2016 y 2017, se observaron las celebraciones del Palo de Mayo, el King Pulanka y la Semana Santa tradicional de los diferentes grupos étnicos Creole, Miskito y Mestizo en la ciudad de Bilwi.

Los criterios de selección en base a las entrevistas se tomaron bajo un rango de edad de 20 -70 años, los hombres que fueron entrevistados son el historiador Avelino Cox cuyos conocimientos en base a la cultura Miskitu es de gran interés para esta investigación, el Padre de la iglesia católica, con esas excepciones todas las demás entrevistas son aplicada a mujeres. Ser pertene- 
ciente a los grupos étnicos, Miskitu, Creole y Mestizo de la ciudad de Bilwi Puerto Cabezas forman parte de los criterios, los informantes claves, fueron:

Mayordoma de la iglesia católica, con el objetivo de conocer su trabajo dentro de la iglesia y el papel de las mujeres dentro de la misma, el Historiador Avelino Cox, pues brinda un amplio conocimiento en base al sistema de creencias del grupo étnico Miskitu y el papel de la mujer dentro del mismo, mujer Creole Sara Juanita Broock Flores forma parte de las informante claves pues logró brindar información en base a su cultura ancestral y su familia intercultural forma parte de las primeras familias dentro de la ciudad de Bilwi, y Deyra Kristin Fuller Mujer Miskita Pikinera.

Dentro de la metódica es necesario mencionar el método estadístico, consiste en el manejo de una serie procedimientos de los datos cualitativos y cuantitativos de la investigación, dentro del cual se aplicó la encuesta como instrumento más conocido dentro de este método.

Las etnias seleccionadas de igual forma fueron Miskitu, Mestizos, Creole con las que se trabajan dentro de la investigación. Un criterio de Aplicabilidad de encuestas, 30 encuestas por grupo étnico, divididas 15 a hombres y 15 a mujeres.

En estas ocasiones se logra observar la participación abierta de todos los miembros de la población sin importar su origen étnico. Por ejemplo, en las festividades del King Pulanka llegan los misquitos, que viven en las comunidades de la región, como por ejemplo miembros de las comunidades de Yulu, Tuara etc, y algunos Miskitos de Honduras. En la festividad del King Pulanka se rememora el reinado Miskito en Puerto Cabeza, se comparte y saborea la gastronomía, baile, rituales y artesanía Miskita.

En el Palo de Mayo, los Creole dan tributo a la diosa de la fertilidad y la naturaleza Mayaya. Por otra parte, la Semana Santa es una festividad religiosa en la que se identifican más los mestizos sin embargo tanto Creoles como Miskitos son partícipes de ella debido a las creencias religiosas. Tanto hombres y mujeres son organizadores y actores en estas festividades pertenecientes a sus grupos étnicos originarios, observando las practicas vivida en la ciudad como medio de relaciones sociales y de interacción socio cultural.

\section{Resultados}

Las mujeres Miskitas, Creoles y Mestizas son las principales actoras en este caso, cada una de ellas presenta su acervo de prácticas y conocimientos ancestrales en cuanto a su cultura y como lo aplican en la cotidianidad de su vida diaria.

La identidad cultural es fundamental, las mujeres por mucho tiempo han logrado el compartir y difundir sus prácticas culturales con sus familias, de esta forma no solo fortalece este conocimiento, logran una aplicación del mismo en su diario vivir, muchas veces no es percibido; sin embargo, el legado cultural está latente. Las mujeres en este caso tienen su propia visión de estas prácticas en 
relación a su cultura y como ésta es expresada, por tal motivo veremos a los diferentes grupos étnicos bajo la cosmovisión de las mujeres Miskitas, Creole y Mestiza.

\section{Interacciones interculturales}

Cuando hablamos de interacciones interculturales, estamos haciendo referencia a ese intercambio de conocimientos culturales que están presentes dentro de una población en este caso en la ciudad de Bilwi.

Los conocimientos culturales pueden estar basados en diversos temas; sin embargo, en este particular se presentan la gastronomía, medicina tradicional y la lengua materna como referente general, debido a que son parte fundamental dentro del contexto intercultural.

Estos datos reflejan que dentro de las relaciones interculturales que se dan dentro de la población los conocimientos culturales adquiridos por lo general y en gran medida son

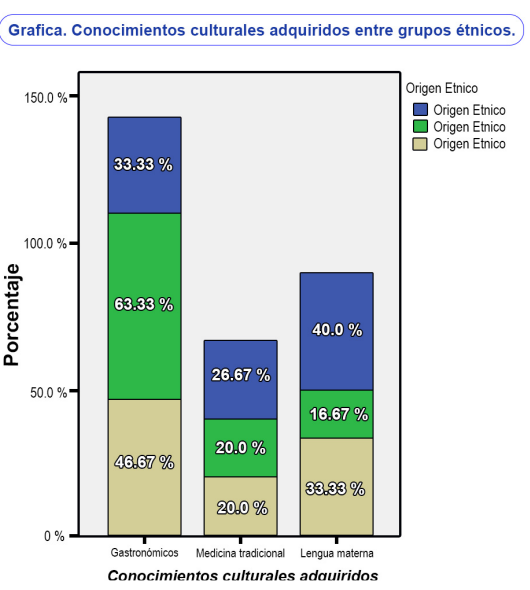
estos tres. Dentro de ellos, hasta los hombres expresan haber adquirido conocimientos gastronómicos debido a las relaciones interculturales a lo largo del tiempo, por parte de sus madres o abuelas.

Las interacciones interculturales hacen énfasis en lo que se adquiere y comparte entre cultural, pero como es visto esto desde la cosmovisión de las mujeres, ya conocemos y tenemos un panorama en relaciona aspectos culturales pertenecientes a cada grupo étnicos, como las mujeres forman parte de estos procesos, como es visto desde los ojos de las mujeres costeñas el contexto cultural, su percepción en relación a la multietnicidad.

\section{Realidades interculturales: identidad costeña}

Parte de la realidad en cuanto a la interculturalidad de las mujeres es debido a la necesidad comunicacional y a la educación familiar intercultural que es parte de la realidad de las estructuras familiares en la ciudad de Bilwi. Para explicar un poco estas características en cuanto a las familias presentamos un diagrama de parentesco de una familia Miskita que

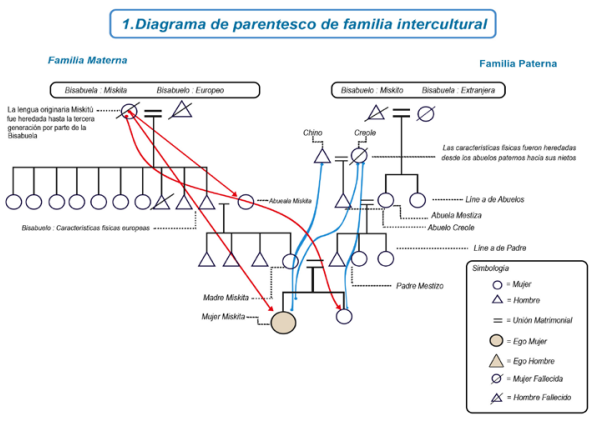
tiene dentro de su conformación familiar orígenes extranjeros, , europeos, chino y creole.

Las relaciones interculturales entre las mujeres costeñas están presentes desde pequeñas, el acercamiento a otras culturas está en los diferentes espacios sociales, públicos y privados dentro de la ciudad. Debido a esto es 
inevitable que entre mujeres no exista socialización e interacción de forma directa o indirecta en este caso la conformación familiar inter-étnica.

La perspectiva en base a la cultura de las mujeres de un grupo étnico diferente al propio es asimilada, podemos identificar que las mujeres costeñas tienen conocimientos amplios en base a la cultura de las otras y sus diferentes prácticas dentro de lo familiar.

Las mujeres costeñas presentan una perspectiva abierta en relación a las relaciones interculturales, esto podría ser parte de la conciencia cultural que se tienen en base al contexto multiétnico.

\section{La mujer costeña}

Las mujeres costeñas han luchado para la deconstrucción de ese pensamiento discriminatorio relacionado a sus orígenes étnicos en los espacios de participación laboral, pues es una realidad que muchas veces las características físicas juegan un papel muy importante a la hora de aplicar para un puesto laboral, o de cierta forma no se valora el trabajo que se realiza.

Se logró observar el cambio de perspectiva que tienen las mujeres y el reconocimiento de cómo eran vistas en su cultura y las barreras culturales que se les presentaban por el hecho de ser mujer en cuanto al trabajo fuera del hogar.

Dentro del "Ser Mujer" hay muchos aspectos a tratar, uno de ellos es la identidad y en este caso. La identidad cultural es el conjunto de medios por los cuales un individuo se describe así mismo (Ramírez, 1993). De manera general se presenta que es la identidad cultural; sin embargo, aquí se aborda la identidad desde la mujer, ¿Cómo se identifican las mujeres costeñas?

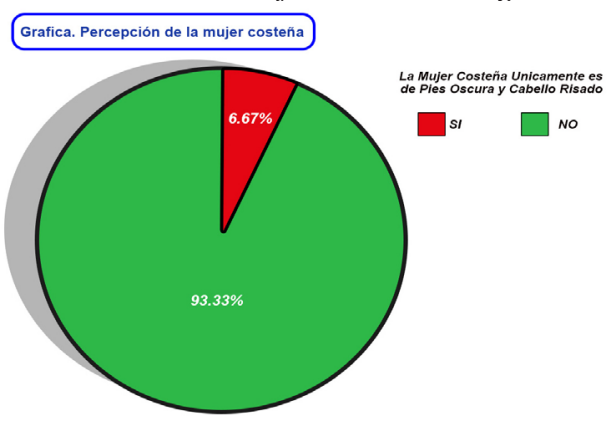

Para esto se realizó una pregunta en relación a las características de las mujeres según características culturales preestablecidas que hay alrededor de las mujeres de la Costa Caribe de Nicaragua, donde las mujeres Costeñas de la ciudad de Bilwi expresaron su opinión.

En base a estos resultados, se procedió a preguntarle a las mujeres costeñas de la ciudad de Bilwi, ¿Cómo identifican a la mujer costeña?, mediante entrevistas abiertas

Raquel Francis Gutiérrez de origen Miskitu expresa: "La mujer costeña es la que nace aquí, no importa el color, la etnia o su lengua, si nace aquí rodeada de nuestra cultura es de aquí, cien por ciento" (Gutiérrez, 2017). 
Al igual que muchas mujeres Doña Devora Webster Palmer, mujer de origen étnico creole, expresa un poco acerca de la percepción de la que se aborda en relación a las mujeres de Costa Caribe

"Pues antes la misma gente decía; que las mujeres costeñas son negras, altas, cabello crespo; pero creo que eso ha venido cambiando, porque ya ven que hay mujeres Miskitas, que son morenas, cabello liso, e incluso hay unas de piel clara y chinas, las mujeres Mestizas y las mujeres Mayangnas que también tienen características diferentes" (Palmer, 2017).

El sentido de pertenencia entre las mujeres es expresado, la inclusión de la heterogeneidad cultural que forma parte de cada grupo étnico en uno solo es parte de la identidad de las mujeres en la ciudad de Bilwi.

Estas son expresiones de la identidad intercultural de las Mujeres costeñas, desde su propia cosmovisión en base a su realidad dentro de su diario vivir, la ciudad de Bilwi representa un contexto multiétnico con mujeres que tienen su propia percepción en cuanto a las relaciones interculturales y su cultura originaria. El ser mujer costeña representa la heterogeneidad cultural.

\section{Conclusiones}

A lo largo de esta investigación da cuenta de diversos aspectos que influyen en el hacer de las mujeres costeñas en diferentes espacios dentro de su vida cotidiana están ligados a la interculturalidad, no solo desde la existencia de diversos grupos étnicos dentro de la Ciudad de Bilwi, si no que la coexistencia, las relaciones interculturales y conformaciones familiar inter-étnicas crean una visión cultural que no solo pertenece a su grupo étnico originario, sino que también contempla las realidades culturales de las demás etnias que las rodean.

En base a las expresiones de la identidad intercultural de las mujeres costeñas se logró identificar que la realidad de la interculturalidad de las mujeres en la Ciudad de Bilwi, está inmersa en la heterogeneidad de la cultura, se ha logrado un balance que logra la interacción intercultural entre las mujeres y esto general un sentido de pertenencia gracias al dialogo intercultural que existe entre sí.

El protagonismo de la mujer costeña, su cosmovisión e identidad cultural, está fuertemente ligados a los procesos interculturales, y estas relaciones interculturales se dan debido a la Inter-etnicidad que se ha creado en la Ciudad.

Podemos concluir que las mujeres costeñas tienen una visión amplia y rica con relación a su cultural y la interculturalidad entre ellas, su cosmovisión esta nutrida en base a las experiencias interculturales que se dan de forma orgánica en su vida cotidiana y dentro de sus familias. 


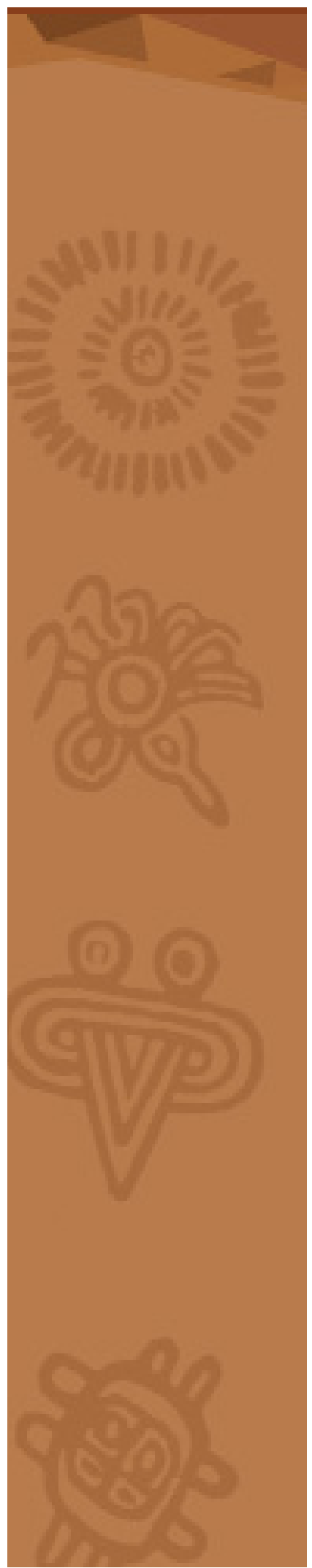

\section{Bibliográfica}

Benk, R. L., Balderramos Rojas, M., \& Espinosa Blanco, S. (2016). Percepción de las mujeres miskitas en el Liwa enWasla, Waspam,. Revista universitaria del caribe , 2.

Harris, M. (1871). Antropologia cultural. londres: primitive culture, j,murray.

Minks, A. (2003). La interculturalidad en el discurso de los niños Miskitos en corn island. WANI , 37.

Barabas, A. M. (2014). Multiculturalismo, Pliralismo cultural y Interculturalidad en el contexto de América Latina: la presencia de los pueblos originarios. configuracoes Revista de sociologia , 2.

Butler, J. (1999). El género en disputa El feminismo y la subversión de la identidad. . Nueva York : Routledge.

Geertz, C. (1973). La interpretación de las culturas . Barcelona : gedisa editorial .

Sánchez, D. R. (2010). El concepto de la cosmovisión . KAIRÓS , 80.

Vázquez, M. E. (2017). Identidad de Género, una Categoria para la Deconstrucción . Xihmai , 94.

Salinas, S. C., \& Juárez Núñez, J. M. (2013). Las interculturalidad-es, identidad-es y el diálogo de saberes . Reencuentro, 21.

\section{Dayaisi Grissell López Ramírez}

Licenciada en Antropologia social titulada en la Universidad Nacional Autónoma de Nicaragua (UNAN-Managua) , comprometida con su labor profesional, investigadora de temas interculturales, género, estudios etnográficos y etnohistóricos realizados en diversos departamentos del país como León, Granada y la Región Autónoma de la Costa Caribe Norte de Nicaragua. Ex becaria del programa de becas de la Universidad Nacional Autónoma de Nicaragua. Ha participado como ponente en diversas Jornadas de Investigación y Congresos Científicos en su periodo de estudiante universitaria, Colaboradora en las actividades de Voluntariado social promovidas por la Facultad de Humanidades y Ciencias Jurídicas, en conjunto con: WORLD VISION, MILAVF, Centro Cultural Batahola Norte, Escuelas Eclesiásticas de Base Y Radio Music Box de la UNAN Mangua. Como profesional en su área de estudio fue ponente en temáticas interculturales y género en el XII Congreso Centroamericano de Antropología, sede Nicaragua con el lema «Hacia un diálogo interdisiplinario para el fortalecimiento de la Antropología» (2019). 